\title{
Peleja entre dois mestres zen-budistas: poemas para o quinto Patriarca
}

Leandro Durazzo

Resumo: Apresentamos, neste pequeno texto, nossa proposta de tradução para os poemas já famosos de dois discipulos do quinto Patriarca do budismo Chan/Zen, um dos quais passou à posteridade como o sexto e talvez mais radical Patriarca da tradição. A importância de tais poemas está no fato de, expressando a compreensão que cada um detinha do Dharma, da doutrina do Buda, terem servido de evidência literária para uma contenda doutrinária bastante importante no budismo do extremo oriente: a disputa entre iluminação súbita, na esteira de Huineng, e gradual, com Shenxiu.

Palavras-chave: Budismo Chan/Zen; Budismo chinês; Religião; Poesia; Literatura Budista

Brevíssima apresentação: porque a iluminação não está nas palavras

A tradição Chan (禅) de budismo chinês, muito conhecida no ocidente por sua descendente japonesa, Zen, é uma linhagem de ensinamentos e práticas que se origina com o próprio Buda histórico, Sakyamuni (por volta do século VI AEC). A história consagrada nos diz que, ao realizar um sermão para a grande assembleia que o assistia, o Buda não pronunciou palavra. Em vez disso, tomou nos dedos uma única flor e a ergueu, para confusão dos que o assistiam.

Mas um discípulo sorriu em resposta, e nesse momento o Iluminado declarou que "o Tesouro do Olho do Verdadeiro Dharma, a Maravilhosa Mente do Nirvana, somente Mahakasyapa compreendeu” (SHENG-YEN, 1998, p. 2,

1 "The Treasure of the Eye of the True Dharma, the Wondrous Mind of Nirvana; only Mahakashyapa understands". SHENG-YEN, Master. In the spirit of Chan: entering the gate of Chan. New York: Dharma Drum Publications, 1998, p. 2. Disponível em: http://immersor.com/cmc/wp-content/uploads/2010/09/ In-the-Spirit-of-Chan.pdf Acessado em: 03/03/2013 
tradução nossa) ${ }^{1}$. Mahakasyapa, assim, tornou-se o primeiro Patriarca do budismo Chan, que mais tarde chegaria à China.

Sobre a palavra Chan (禅), podemos apontar sua origem etimológica como sendo a transliteração fonética de um fragmento da palavra correspondente em sânscrito, dhya na. Esta, por sua vez, indica a meditação e absorção meditativa que resulta da prática das contemplações budistas, do cultivo espiritual. Ainda, o termo originalmente conotava abdicação, sagração de um altar, sacrifício animista (SOOTHIL; HODOUS, 2003). ${ }^{2}$

Mas o futuro sexto Patriarca do Chan chinês, Huineng (惠能; 638-713 EC), sendo um iletrado trabalhador braçal do templo Dongchan, em Huangmei, Qizhou, provavelmente não sabia de etimologias. Em verdade, segundo seu próprio relato, ele não sabia de nada: "estive trabalhando neste moinho pelos últimos oito meses, sem nunca ter entrado no salão do patriarca." (HSING YUN, 2010, p. 8)

Sem entrar no salão do patriarca, sem ouvir seus sermões e palavras, Huineng não sabia que Hongren (弘忍; 601-674 EC) esperava descobrir, entre seus discípulos, alguém que houvesse alcançado a iluminação. Encontrando-o, era sua intenção passar adiante as vestes e o Dharma, nomeando tal discípulo como sexto Patriarca.

A forma pela qual Hongren pretendia encontrar seu sucessor era através de uma expressão poética religiosamente significativa, as gatha (sânscrito; em chinês, 偈 ji), que pedira a todos para criar. Shenxiu (神秀, 606-706 EC), o monge mais velho e experiente da comunidade, compôs uma primeira gatha contra a qual nenhum membro da Sangha, a comunidade monástica budista, ousou escrever. Sendo o mais velho, certamente sua compreensão do Dharma seria a mais perfeita. Ao menos foi o que a comunidade pensou, e apenas o iletrado moleiro propôs uma gatha diferente.

A tradução que apresentamos aqui, embora formalmente imperfeita, procura transmitir o cerne do embate entre os dois discípulos - que viriam a se tornar, ambos, sextos Patriarcas, um do Chan do norte, outro do sul. A tradição costuma considerar a compreensão de Huineng como sublime, por capturar diretamente o

\footnotetext{
2 "Preparar um espaço como altar para sacrifícios às montanhas e fontes; abdicar. Adotado pelos budistas para designar dbyana, 禪 ou 禪那, ou seja, meditação, absorção, transe. Dhyana é 'meditação, pensamento, reflexão, especialmente uma contemplação religiosa profunda e abstrata” (tradução nossa); [禪 To level a place for an altar, to sacrifice to the hills and fountains; to abdicate. Adopted by Buddhists for dhyāna, 禪 or 禪那, i.e. meditation, abstraction, trance. dhyāna is 'meditation, thought, reflection, especially profound and abstract religious contemplation']

3 II have been grinding at this mill for the last eight months and have not walked up to the patriarch's hall]
} 
sentido de uma noção muito cara ao budismo: a vacuidade (sânsc. sunyata; chinês 空 kong). Shenxiu, por sua vez, mostrava-se ainda atrelado à mente discriminativa, que diferencia os fenômenos e busca sua purificação.

Mesmo que ambos tenham se tornado mestres, patriarcas de linhagens razoavelmente distintas, é a Huineng que Hongren passa o manto, a tigela e o reconhecimento da sabedoria profunda. Ainda, sendo a gatha de Huineng uma resposta à de Shenxiu, será nessa ordem que as apresentaremos.

\section{A tradução ${ }^{4}$}

Gatha de Shenxiu

$\begin{array}{ll}\text { Corpo é a árvore bodhi }{ }^{5} & \text { 身是菩提樹, } \\ \text { Coração é tal qual um espelho. } & \text { 心如明鏡臺。 } \\ \text { Diligente, espane-o sempre } & \text { 時時勤拂拭, } \\ \text { Não deixe que a poeira assente. } & \text { 勿使惹塵埃。 }\end{array}$

Gatha de Huineng

Não há cultivo de bodhi ${ }^{6}$,

菩提本無樹,

Nem mesmo espelho brilhante.

明鏡亦非臺

Se nada há de existente,

本來無一物,

Ao que a poeira se prende?

何處惹塵埃。

\section{Referências}

HSING YUN, Venerable Master. The rabbit's horn: a commentary on the Platform Sutra. Hacienda Heights: Buddha's Light Publishing, 2010.

$4 \operatorname{HUINENG}$ (s/d). Original disponível em: http://zbohy.zatma.org/Dharma/zbohy/chinese_text/ book.phtml?_file_dir=platform\&_page_file=1_5 Acessado em: 03/03/2013

$5 \boldsymbol{B} \boldsymbol{B} d \boldsymbol{h} \boldsymbol{i}$, palavra sânscrita para iluminação, donde a raiz $\boldsymbol{b} \boldsymbol{u} \boldsymbol{d} \boldsymbol{b}$ - que forma o epíteto do iluminado $\boldsymbol{B} \boldsymbol{u} d \boldsymbol{d}$, também compõe o nome da árvore sob a qual Sidarta Gautama, o Buda histórico, se iluminou - portanto, árvore da iluminação, árvore bodhi.

6 Em sua resposta, Huineng não apenas nega a substancialidade de uma árvore da iluminação mas, negando também o próprio cultivo de uma iluminação, se opõe doutrinariamente à ideia corrente até então de que, para atingi-la, um ser deveria necessariamente passar por estágios graduais. O sexto Patriarca propõe a iluminação súbita como realização máxima da sabedoria, como insight profundo da realidade. 
HUINENG, Patriarch. Platform Sutra: the Sutra of Huineng. Carson City: Zen Buddhist Order of Hsu Yun, s/d. Disponível em: http://zbohy.zatma.org/Dharma/zbohy/chinese_text/ book.phtml?_file_dir=platform\&_page_file=1_5 Acessado em: 03/03/2013

SHENG-YEN, Master. In the spirit of Chan: entering the gate of Chan. New York: Dharma Drum Publications, 1998, p. 2. Disponível em: http://immersor.com/cmc/wp-content/ uploads/2010/09/In-the-Spirit-of-Chan.pdf Acessado em: 03/03/2013

SOOTHIL, William Edward; HODOUS, Lewis. A dictionary of Chinese Buddhist terms. Tokyo: Japan Society for the Promotion of Science, 2003. Disponível em: http:/ / mahajana. net/texts/kopia_lokalna/soothill-hodous.html Acessado em: 03/03/2013 